\title{
ON THE PROPERTIES OF HOT FORGED Ti-6Al-4V ALLOY AIMED FOR SURGICAL IMPLANTS
}

\author{
Marija Mihailović ${ }^{* 1}$, Aleksandra Patarić ${ }^{2}$ \\ ${ }^{I}$ Institute of Chemistry, Technology and Metallurgy, University of Belgrade, \\ Department of Electrochemistry, Njegoševa 12, 11000 Belgrade, Serbia \\ ${ }^{2}$ Institute for Technology of Nuclear and other Mineral Raw Materials, \\ Franchet d'Eperey St.86, 11000 Belgrade, Serbia
}

Received 22.03.2019

Accepted 29.03.2019

\begin{abstract}
The investigation here is aimed to examine the structural and mechanical changes that might have occurred during the hot forging process, a process to obtain a surgical hip implant, and the subsequent heat treatment. Microstructural characterization, morphological and semi-quantitative chemical analyses have been accomplished using an optical and scanning electron microscope. Chemical analyses of all surfaces obtained by the dotted method in all analyzed samples have shown the approximate equal content of aluminum, titanium, vanadium, iron, and silicon. Tensile testing and measurements were following obtained microstructure, showing the uniformity of microstructure and properties along the forging part, as well as over its cross section. All tests proved that hot forging could be a suitable procedure for surgical implants processing.
\end{abstract} implants.

Keywords: Ti-6Al-4V alloy; biocompatible; hot forging; microstructure; surgical

\section{Introduction}

Well known by its application in demanding operating conditions, due to high specific strength and fracture toughness, low Young modulus and excellent corrosion resistance, the titanium Ti-6Al-4V alloy is also light weighted, with low tissue toxicity and good formability. Hence, it found its application in the production of biocompatible surgical implants and auxiliary medical equipment. Titanium is known by its structural $\alpha$ (hexagonal close-packed structure) to $\beta$ (body-centered cubic structure) transformation at $882,5^{\circ} \mathrm{C}$. There are alloying elements such as $\mathrm{Al}$ and $\mathrm{O}$, which are known as $\alpha$-stabilizers, as well as Mo and V, known as the $\beta$-stabilizers. The Ti-6Al-4V alloy used for implants

* Corresponding author: Marija Mihailović, marija.mihailovic@ihtm.bg.ac.rs 
is $\alpha+\beta$ alloy. It is a heat-treatable alloy that attaining designed properties by the appropriate thermo-mechanical regime.

Because of the high melting point and very high reactivity of titanium and its alloys at those temperatures, this is a material difficult to process $[1,2]$. The investment casting process is reported to be the most advanced process to obtain net-shape parts with complex geometry and superb mechanical properties. However, the appearance of a hard layer, so-called $\alpha$-case, at the surface of a surgical implant is reported [3]. It is a hard and brittle layer, caused by oxygen dissolved in titanium nearby the surface, and can be the spot for crack initiation. Because of it, the machining removal of this layer is necessary for the reliability of the implant produced in such a way. It introduces additional technological operation as well as the costs. Compared to other metals and alloys, titanium alloys, besides its high cost, are poor in machinability and demand high machining costs [2].

It is suggested to develop new kind of shell molds for investment casting process [3], but even further, it is necessary to develop a new net-shape process for obtaining surgical implants with complex geometry and reliable mechanical properties. Although the forging process is already used in the aircraft industry for reliable parts production from Ti-6Al-4V alloy, there are issues in fundamental and technological field to resolve, since titanium is known as material difficult for forging.

Depending on required mechanical properties, the heat treatment can be applied to Ti-6Al-4V alloy, and it is as follows: partial annealing (from 600 to $650{ }^{\circ} \mathrm{C}$ ), full annealing (from 700 to $850{ }^{\circ} \mathrm{C} /$ furnace cooling to $600{ }^{\circ} \mathrm{C}$ /air cooling) or solutionizing (from 880 to $950{ }^{\circ} \mathrm{C} /$ water quenching) and ageing (from 400 to $600{ }^{\circ} \mathrm{C}$ ) [4-9].

\section{Experimental}

The chemical composition of the used alloy is given in Table 1. It is very clean, extra low interstitial free (ELI) alloy.

Table 1. Chemical composition of the Ti-6Al-4V alloy in wt \%

\begin{tabular}{lllllllll}
\hline $\mathrm{Al}$ & $\mathrm{V}$ & $\mathrm{Fe}$ & $\mathrm{Si}$ & $\mathrm{Ti}$ & $\mathrm{C}$ & $\mathrm{N}$ & $\mathrm{O}$ & $\mathrm{H}$ \\
\hline 5.64 & 3.96 & 0.16 & 0.09 & rest & 0.010 & 0.006 & 0.011 & 0.0032 \\
\hline
\end{tabular}

Hot forging was carried out in the $\alpha / \beta$ temperature range, at approximately $950{ }^{\circ} \mathrm{C}$, with forging tools preheated to $100{ }^{\circ} \mathrm{C}$. The procedure was performed using industrial forging hammer powered by compressed air, forging hammer and anvil were coated with glass based protective and lubricating glaze to provide protection, insulation, and lubrication during hot forging.

Samples were taken out at four different points along the forging, to encompass different forging thickness and shape.

The microstructure was examined using optical microscope Inovatest MM650, scanning electron microscope JEOL JSM $6610 \mathrm{LV}$ and semiquantitative chemical analysis was carried out in central and outer areas of each sample.

Mechanical testing included the determination of the basic mechanical properties: the reduction in cross-sectional area $\left(\mathrm{S}_{0}\right)$, the ultimate tensile strength $\left(\mathrm{R}_{\mathrm{m}}\right)$, the yield strength, $\left(\mathrm{R}_{\mathrm{p}}\right)$, and the elongation at break $(\mathrm{A})$. 
Tensile testing and measurements were carried out using the Zwick / Roell Z 100 universal testing machine equipped with software for data processing.

\section{Results and Discussion}

The forged part was rather complicated in geometry. It is so called stem - a body of the hip prosthesis. Sampling was done so to encompass the center and the edge of the forged part at several cross-section points, with different geometry and stem thickness. Different material flows, as well as cooling rates, could have been observed in this way. Hot forging prevents the strain hardening, which is usual for cold forging and resulting in increased machining difficulty.

There is no difference in the microstructure between the core of the sample and the surface of the examined area, Fig. 1 and 2. They are just the representation of the several examined pairs of core/edge microstructure, showing the absence of detrimental alphacase at the surface.

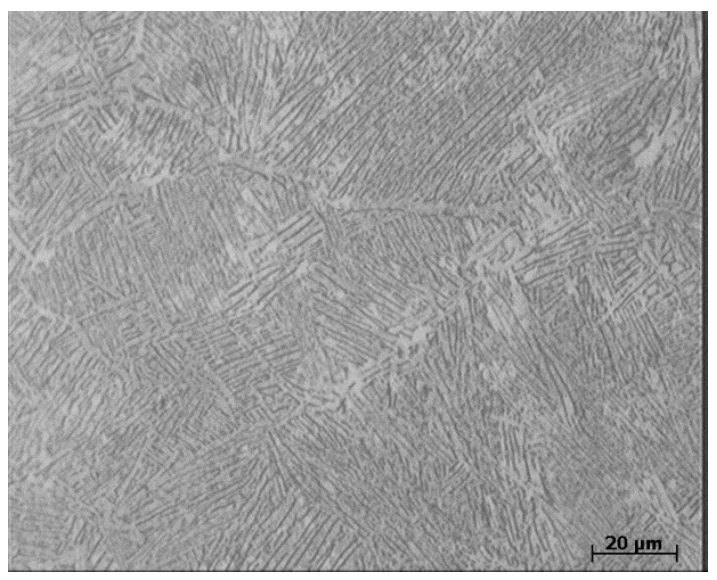

Fig. 1. The microstructure of Ti-6Al-4V; the core of the sample.

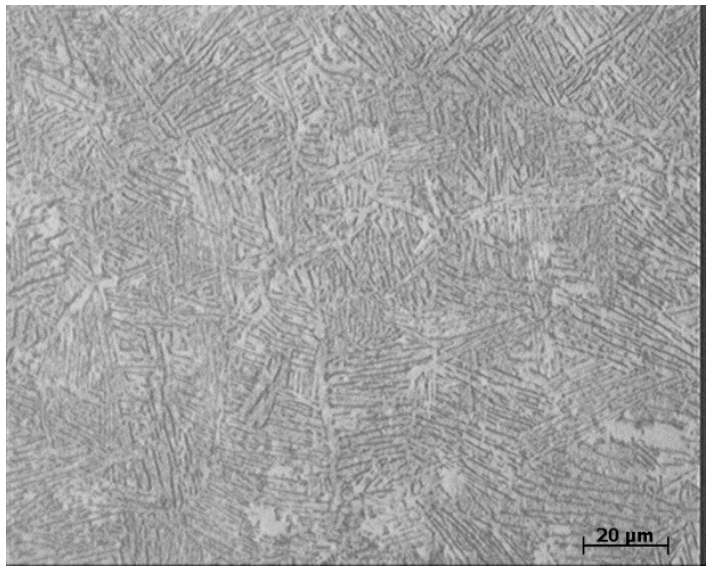

Fig. 2. The microstructure of Ti-6Al-4V; the edge of the sample. 
The Widmanstätten $\alpha$ platelets in primary $\beta$-grains, with white areas of $\alpha$-phase on the grain boundary, is present in microstructure shown in these figures.

The presence of $\alpha / \beta$ transformation in this alloy can induce the presence of a wide range of microstructures, and hence the mechanical properties. The advantage is that through a proper thermo-mechanical regime, the preferred properties for a specific purpose can be attained, Fig. 3.

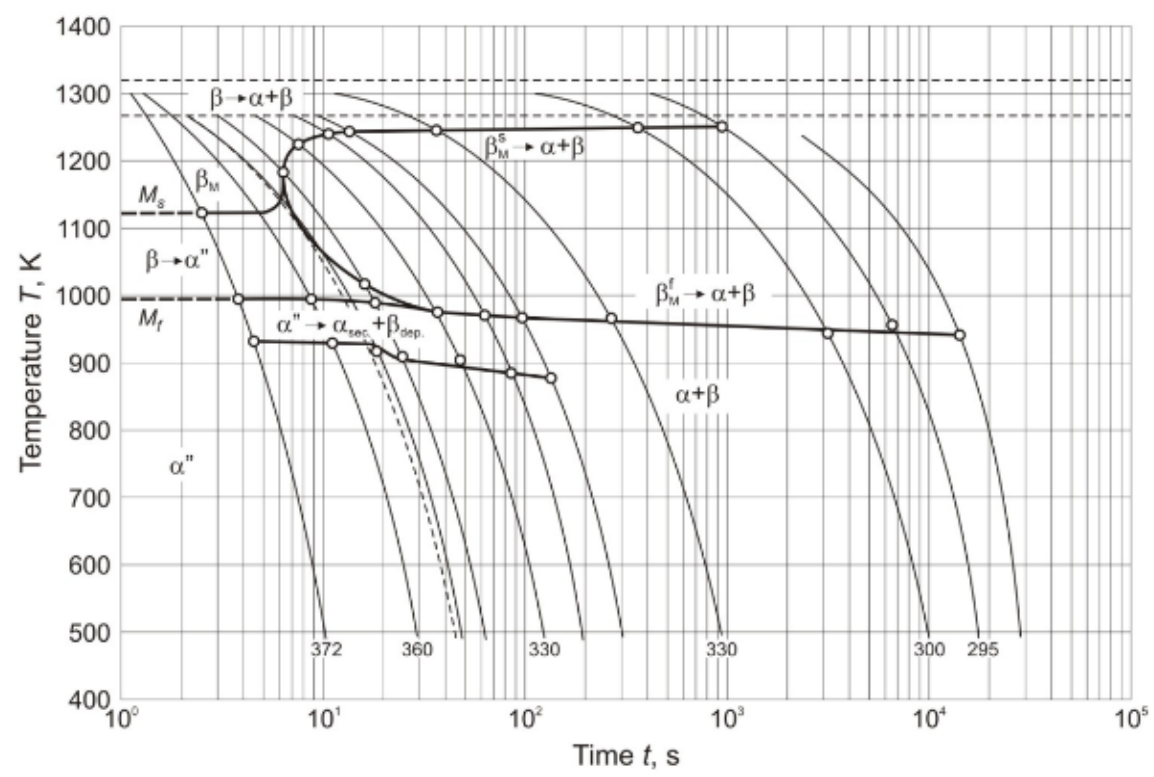

Fig. 3. CCT diagram for Ti-6Al-4V alloy [4].

The yield strength of Ti-6Al-4V alloy lowers rapidly with temperature, making it formable at intermediate temperatures [5-7].

In the case of the alpha-case formation at the surface, it must be removed after processing. It is a hard and brittle layer and can be the place for crack initiation what impairs the properties of any reliable part. Due to the anvil-forging hammer chamber closed to oxygen access at elevated temperatures, and adequate cooling rate, the presence of alpha-case is not registered at the surface of forged parts. It is the layer that can reach depth up to $200 \mu \mathrm{m}$ in the case of samples obtained by investment casting.

Samples for mechanical tests were taken from the thinner central part of the stem, i.e., the neck (sample 1) and a thicker part near the acetabulum (sample 2). 


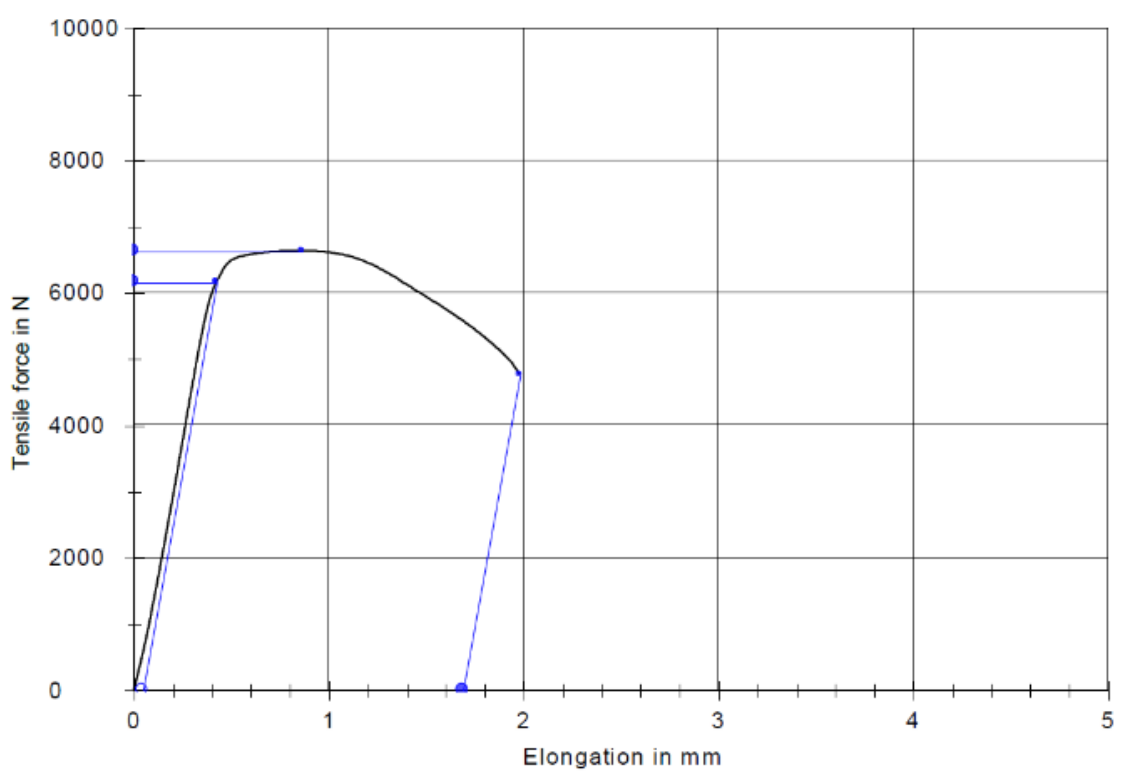

(a)

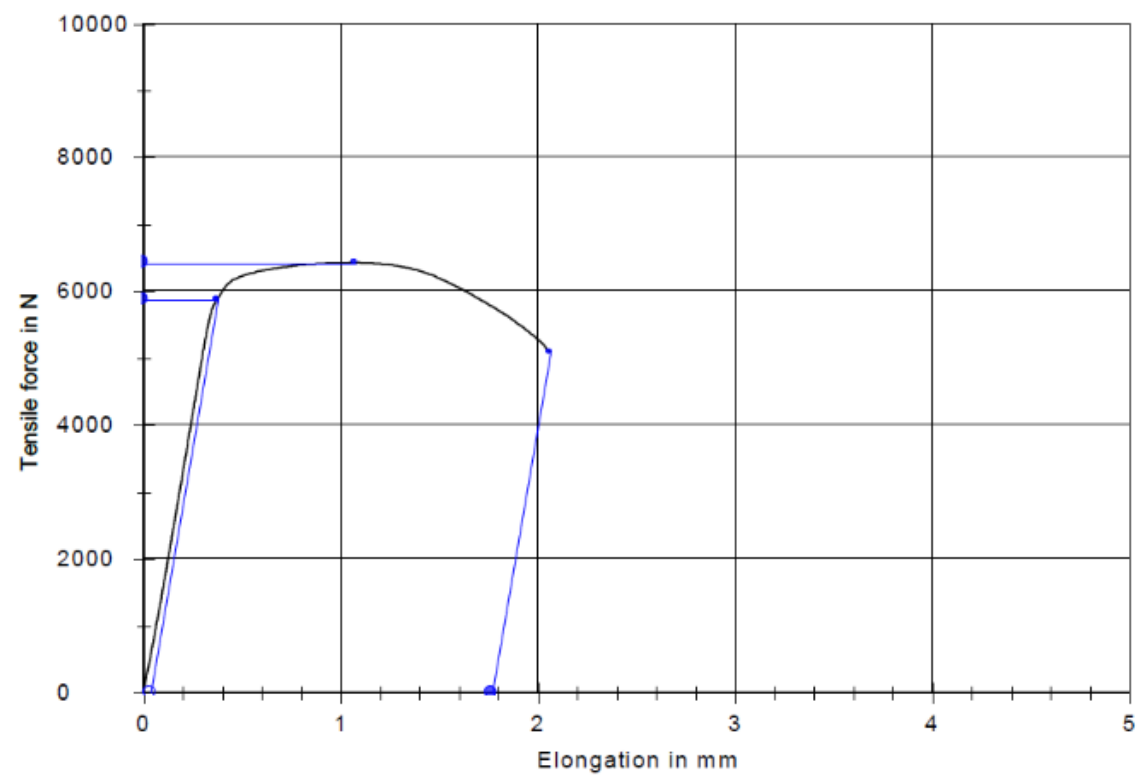

(b)

Fig. 4. Ultimate tensile strength curves for (a) sample 1, (b) and sample 2.

Measured values of the mechanical properties for samples 1 and 2 are shown in Table 2. Based on the obtained values of the measured mechanical properties, and 
following Fig. $4 \mathrm{a}$ and $4 \mathrm{~b}$ for the ultimate tensile strength of the samples 1 and 2 , it can be concluded that there is no significant difference in obtained results of the mechanical properties for samples 1 and 2, which is by the obtained homogeneous microstructure and uniform distribution of alloying elements.

Table 2. Measured values of the mechanical properties for samples 1 and 2 .

\begin{tabular}{lcccc}
\hline $\begin{array}{l}\text { Sample } \\
\text { no. }\end{array}$ & $\begin{array}{c}\mathrm{S}_{0} \\
\mathrm{~mm}^{2}\end{array}$ & $\begin{array}{c}\mathrm{Rm} \\
\left(\mathrm{N} / \mathrm{mm}^{2}\right)\end{array}$ & $\begin{array}{c}\mathrm{Rp} 0.2 \\
(\mathrm{Mpa})\end{array}$ & $\begin{array}{c}\mathrm{A} \\
(\%)\end{array}$ \\
\hline 1 & 7.31 & 907.61 & 842.82 & 13.67 \\
2 & 7.07 & 908.44 & 830.69 & 15.28 \\
\hline
\end{tabular}

Moreover, the results of the semi-quantitative analysis by scanning electron microscopy at different positions on the sample are shown in Table 3. There is no difference between the main alloying elements distribution, no matter whether the analysis was taken in the central area of the sample or at either sample edge. The homogeneous composition is by observed microstructure, as over the cross section of each sample, so between all the samples taken along the forged stem.

Table 3. The chemical composition of the Ti-6Al-4V alloy, in wt. \%

\begin{tabular}{lrrrrr}
\hline $\begin{array}{l}\text { A position of taken EDS } \\
\text { analysis of the sample }\end{array}$ & $\mathrm{Al}$ & $\mathrm{Ti}$ & $\mathrm{V}$ & $\mathrm{Fe}$ & $\mathrm{Si}$ \\
\hline Center & 5.73 & 90.16 & 3.98 & 0.12 & 0.11 \\
Left edge & 5.79 & 90.04 & 3.93 & 0.13 & 0.11 \\
Right edge & 5.77 & 90.16 & 3.80 & 0.16 & 0.11 \\
\hline
\end{tabular}

\section{Conclusion}

Hot forging od the Ti-6Al-4V alloy aimed for surgical implants was carried out in the $\alpha / \beta$ temperature range, at approximately $950{ }^{\circ} \mathrm{C}$, with forging tools preheated up to $100{ }^{\circ} \mathrm{C}$. The Ti-6Al-4V forgings were cut to examine the microstructure and the mechanical properties of the cross-section for different thickness of the forged part.

There is neither difference in the microstructure nor in the mechanical properties between the core of the sample and the surface area, as well as between thinner and thicker stem parts. There was not registered the presence of detrimental alpha-case at the surface. There is no evident difference in main alloying elements distribution in the central area of the sample or at either sample edge, indicating that the homogeneous composition is obtained across the whole cross-section of the forging, as well as all along the forged stem. The correlation microstructure-mechanical properties were proven by tensile strength testing.

This investigation indicates that the hot forging procedure below the $\beta$ transition temperature (BTT) of Ti-6Al-4V alloy can be suitable for producing biocompatible surgical implants.

\section{Acknowledgments}

The authors wish to acknowledge the financial support from the Ministry of Education and Science of the Republic of Serbia through the project TR 34002. 


\section{References}

[1] M.T. Jovanović, S. Tadić, S. Zec, Z. Mišković, I. Bobić: Mater Design, 27 (2006) 192-199.

[2] T. Choda, H. Oyama, S. Murakami: Kobelco Technology Review, 33 (2015) 44-49.

[3] Z. Mišković, B. Dimčić, I. Bobić, S. Zec, M.T. Jovanović: Mater Sci Forum, 494 (2005) 561-566.

[4] J. Sieniawski, W. Ziaja, K. Kubiak and M. Motyka., in Materials Science, Metals and Nonmetals, Titanium Alloys - Advances in Properties Control, ed. J. Sieniawski, W. Ziaja Published: INTECH open science, May 15, (2013) Chapter 4.

[5] D. J. Schrock, D. Kang, T.R. Bieler, P. Kwon: J Manuf Sci Eng, 136 (4) (2014) 041018.

[6] M.G. da Silva, K.T. Ramesh: Mat Sci Eng, A232 (1997) 11-22.

[7] S.K. Kar, A. Ghosh, N. Fulzele, A. Bhattacharjee: Mater Char, 81 (2013) 37-48.

[8] A. Andrade, A. Morcelli, R. Lobo: Revista Matér, 15 (2) (2010) 364-370.

[9] D. Banerjee, J.C. Williams: Acta Mater, 61 (2013) 844-879.

[10] L. Zenga, T.R. Bielerb: Materials Science and Engineering A, 392 (2005) 403-414.

$$
\text { (C) (i) Creative Commons License }
$$

This work is licensed under a Creative Commons Attribution 4.0 International License. 